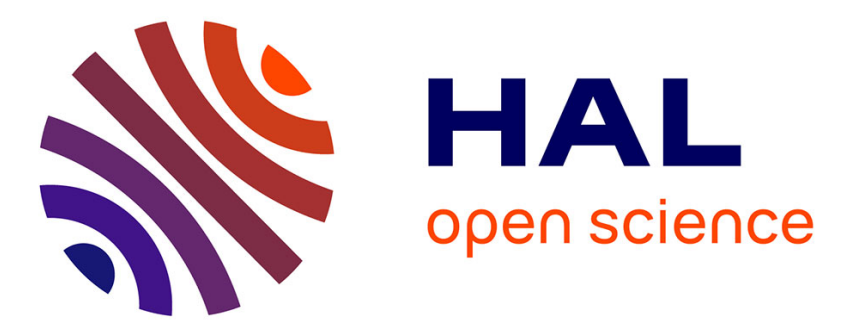

\title{
Development of a second generation in-flight icing simulation code
}

Héloïse Beaugendre, François Morency, W. G. Habashi

\section{To cite this version:}

Héloïse Beaugendre, François Morency, W. G. Habashi. Development of a second generation in-flight icing simulation code. Journal of Fluids Engineering, 2006, 128 (2), pp.378-387. inria-00337571

\section{HAL Id: inria-00337571 \\ https://hal.inria.fr/inria-00337571}

Submitted on 7 Nov 2008

HAL is a multi-disciplinary open access archive for the deposit and dissemination of scientific research documents, whether they are published or not. The documents may come from teaching and research institutions in France or abroad, or from public or private research centers.
L'archive ouverte pluridisciplinaire HAL, est destinée au dépôt et à la diffusion de documents scientifiques de niveau recherche, publiés ou non, émanant des établissements d'enseignement et de recherche français ou étrangers, des laboratoires publics ou privés. 


\section{DEVELOPMENT OF A SECOND GENERATION IN-FLIGHT ICING SIMULATION CODE}

Héloïse Beaugendre

Computational Fluid Dynamics Laboratory, Department of Mechanical Engineering

McGill University

688 Sherbrooke Street West, $7^{\text {th }}$ floor

Montréal, Québec

H3A 2S6

Canada

Now at:

MAB, bureau 281

Université Bordeaux 1

351, cours de la libération

33405 Talence cedex

France

François Morency

Computational Fluid Dynamics Laboratory, Department of Mechanical Engineering

McGill University

688 Sherbrooke Street West, $7^{\text {th }}$ floor

Montréal, Québec

H3A 2S6

Canada

Phone: (514) 398-7314

\section{Corresponding author:}

Wagdi G. Habashi

Director, Computational Fluid Dynamics Laboratory, Department of Mechanical Engineering McGill University

688 Sherbrooke Street West, $7^{\text {th }}$ floor

Montréal, Québec

H3A 2S6

Canada

Phone: (514) 398-3747 
Development of a Second Generation In-flight Icing Simulation Code

\section{ABSTRACT}

Two-dimensional and quasi-3D in-flight ice accretion simulation codes have been widely used by the aerospace industry for the last two decades as an aid to the certification process. The present paper proposes an efficient numerical method for calculating ice shapes on simple or complex_3D geometries. The resulting ice simulation system, FENSAP-ICE, is built in a modular fashion to successively solve each of flow, impingement and accretion via field models based on partial differential equations (PDEs). The FENSAP-ICE system results are compared to other numerical and experimental results on 2D and slightly complex 3D geometries. It is concluded that FENSAP-ICE gives results in agreement with other codes calculation results, for the geometries available in the open literature.

\section{INTRODUCTION}

As not all certification conditions can be ice tunnel-tested, flight-tested, tanker-tested nor encountered in natural icing testing, the certification process usually consist of a mix of experimental and numerical methods that make it possible to explore, safely, the entire combined aerodynamic and icing envelopes. Since more than 50 years now, the aircraft icing community has been using analytical methods to calculate impingement limits and predict ice shapes to be attached to an aircraft for flight-testing[1]. The decrease in computer calculation cost has led to the rapid development of ice accretion simulation tools in the early 80's[2]. Usually, such methods are based on either a 2D or quasi-3D inviscid flow codes (Panel method) to compute the airflow solution, on Lagrangian particle tracking techniques for droplet impingement calculations, and on a 1-D mass and heat transfer balance at the surface to predict ice shapes. The best-known codes using this structure are NASA's LEWICE[3], ONERA[4] and Bombardier Aerospace's CANICE[5].

Although code structure has remained mostly the same for nearly 20 years, several improvements have been proposed, making it possible for the most advanced codes to tackle 3D problems [6]. One of the advantages of these pioneering methods is their fast calculation speed, especially on 2D problems. They have, however, known limitations, the most obvious being the inability to handle flow with separation. It is well known that viscous/non-viscous coupling methods are difficult to apply to separated flow, more the norm than the exception in most of the glaze ice accretion cases.. 
Development of a Second Generation In-flight Icing Simulation Code

Current CFD technologies can overcome some of the limitations of these fully mature methods, and open new possible uses for inflight icing prediction tools. Advanced notions such as using CFD to couple aerodynamics and icing, of using CFD to assess the stability and control of iced aircraft or of building a CFD-database for an in-flight icing simulator can then be contemplated.

The FENSAP-ICE approach views icing accretion simulation as the interlinked solution of:

- The computation of the clean and degraded flows via a 3D compressible turbulent Navier-Stokes equations (by any CFD code; here with FENSAP [7]: Finite Element Navier-Stokes Analysis Package)

- $\quad$ The computation of the collection efficiency by a 3D Eulerian method (here with DROP3D [8])

- The solution of 3D mass balance and heat transfer at surface, using partial differential equations, for prediction of 3D ice accretion shapes (here with ICE3D [9])

- A conjugate heat transfer problem, in the presence of an anti-icing heat flux across the wing skin (for example, with the use of CHT3D [10])

all four approaches being Partial Differential Equations (PDE)-based. As shown in Fig. 1, the modules are set in an interactive loop.

This paper first presents a short description of the first three modules. The code results are compared to other 2D and Quasi-3D numerical and experimental results from NASA, and are demonstrated for ice accretion on a 3D rotor blade tip..

\section{FENSAP-ICE'S MODULES DESCRIPTION}

\section{AIRFLOW SOLVER}

The airflow solver of FENSAP-ICE, FENSAP, can act in an inviscid (Euler) or viscous (Navier-Stokes) mode, as necessitated by the application at hand. For ice accretion simulation, results are extremely sensitive to the turbulent heat fluxes at walls and the Navier-Stokes equations, with appropriate turbulence models, are called for. Currently, a one-equation turbulence model (SpalartAllmaras [11]), including extension for rough-wall treatment [12], has been implemented and successfully validated [13]. The validation has been done against experimental and numerical results on an attached flow with known equivalent sandgrain roughness value. Glaze ice accretion simulation results depend on the roughness value selected, and an empirical correlation relating roughness to velocity, liquid water content and static temperature, developed for LEWICE, is used [13, 14].

Spatial discretization is carried out by FEM and the nonlinear governing equations are linearized by a Newton method. To advance the solution in time, an implicit Gear scheme is used, along with a generalized minimum residual (GMRES) procedure to iteratively solve the resulting linear equations matrix system. In order to have a nearly optimal mesh for a required number of nodes for a Navier- 
Development of a Second Generation In-flight Icing Simulation Code

Stokes calculation, an automatic anisotropic mesh optimization procedure is used [15]. This technology has been shown to yield userindependent and solver-independent results as long as one is not limited in mesh size. When computer memory constrains the problem size, then mesh adaptation provides a rapid way to generate meshes that optimize the prediction of a known scalar physical property of the flow, most often the Mach number.

Gradients needed for heat fluxes at walls are also accurately calculated via a consistent FEM post-processing approach developed by Gresho et al [16]. This method substantially reduces the numerical error in flux evaluation. Good results will be obtained if the physical models, including heat fluxes and the turbulence model, are appropriate for the problem. It is generally admitted that one- and two-equation turbulence models have difficulties to accurately predict the flow field in a separated region, such as the flow behind an ice horn or ridge, but potential flow methods completely fail in these cases.

\section{DROPLET FLOW SOLVER}

The Eulerian droplet impingement model is essentially a two-fluid model consisting of the Euler (inviscid) or Navier-Stokes (viscous turbulent) set of equations for dry air, augmented by the following droplet-specific continuity and momentum equations:

$$
\begin{gathered}
\frac{\partial \alpha}{\partial t}+\nabla \cdot\left(c \mathbf{u}_{d}\right)=0 \\
\frac{D \mathbf{u}_{d}}{D t}=\frac{C_{D} \operatorname{Re}_{d}}{24 K}\left(\mathbf{u}_{a}-\mathbf{u}_{d}\right)+\left(1-\frac{\rho_{a}}{\rho_{w}}\right) \frac{1}{F r^{2}} \mathbf{g} \\
+\frac{\rho_{a}}{\rho_{w}} \frac{D_{a} \mathbf{u}_{a}}{D t}
\end{gathered}
$$

where the variables $\alpha$ and $\mathbf{u}_{d}$ are mean values, respectively, of the non-dimensional water volume fraction and droplet velocity over a small fluid element around the location $x$ at time $t$. The first term on the right-hand-side of Eq. (2) represents the drag force on the droplets, while the second and third terms represent, respectively, the buoyancy force from gravity and the forces exerted on an air particle that would have occupied the volume of the droplet [17]. In most cases, the third term is negligible due to the low ratio of air to water densities.

An empirical correlation is used for the drag coefficient, $C_{D}$. The two-fluid model assumes spherical monodispersed droplets, at the median volumetric diameter of the sample size distribution. The spherical droplet approximation is valid for droplet Reynolds numbers below 500. No collision or mixing between the droplets is accounted for, as these are not significant in certification icing situations. The following empirical equation gives the drag coefficient around a sphere, as a function of the Reynolds number: 
Development of a Second Generation In-flight Icing Simulation Code

$$
\begin{aligned}
& C_{D}=\left(24 / \operatorname{Re}_{d}\right)\left(1+0.15 \mathrm{Re}_{d}^{0.687}\right) \text { for } \mathrm{Re}_{d} \leq 1300 \\
& C_{D}=0.4 \quad \text { for } \operatorname{Re}_{d}>1300
\end{aligned}
$$

The correlation used goes above $\mathrm{Re}_{\mathrm{d}}=500$ because on during the iterative convergence of the numerical solution, higher droplet Reynolds numbers Table may occur. The final converged solution, however, should not contain local droplet Reynolds numbers above 500. Otherwise, it means that a different correlation accounting for droplet deformation must be used.

The non-dimensional air velocity, $\mathbf{u}_{\mathbf{a}}$, is obtained from the solution of the Navier-Stokes equations. Because of the low liquid water concentration, the effect of the droplets on the airflow is neglected. Airflow can thus be determined before solving Eq. (1) and Eq. (2).

A finite element Galerkin formulation is used to discretize the set of Eq. (1) and Eq. (2), with a streamline upwinding PetrovGalerkin (SUPG) term added [18].

\section{ICE ACCRETION SOLVER}

The 3D partial- differential equation-based equilibrium model introduced in reference [19] is derived based on the Messinger [1] model. It has been further improved to predict the ice accretion and water runback on the surface [9]. The velocity $\mathbf{u}_{f}$ of the water in the film is a function of coordinates $\mathbf{X}=\left(x_{1}, x_{2}\right)$ on the surface and $y$ normal to the surface.

A simplifying assumption consists of taking a linear profile for $\mathbf{u}_{f}(\mathbf{x}, y)$, with a zero velocity imposed at the wall, i.e.:

$$
\mathbf{u}_{f}(\mathbf{x}, y)=\frac{y}{\mu_{w}} \tau_{\text {wall }}(\mathbf{x})
$$

where $\tau_{\text {wall }}$, the shear stress from the air, is the main driving force for the water film.

By averaging across the thickness of the film, a mean water film velocity is obtained:

$$
\overline{\mathbf{u}}_{f}(\mathbf{x})=\frac{1}{h_{f}} \int_{0}^{h_{f}} \mathbf{u}_{f}(\mathbf{x}, y) d y=\frac{h_{f}}{2 \mu_{w}} \tau_{\text {wall }}(\mathbf{x})
$$

The resulting system of partial differential equations is thus the following mass conservation and energy conservation equations:

$$
\rho_{w}\left[\frac{h_{f}}{a}+\operatorname{div}\left(\tilde{\mathbf{u}}_{f} h_{f}\right)\right]=U_{\infty} L W C \beta-m_{\text {evap }}-m_{i c e}
$$




\section{Development of a Second Generation In-flight Icing Simulation Code}

where the three terms on the right-hand-side correspond to the mass transfer by water droplet impingement (source for the film), the evaporation and the ice accretion (sinks for the film), respectively.

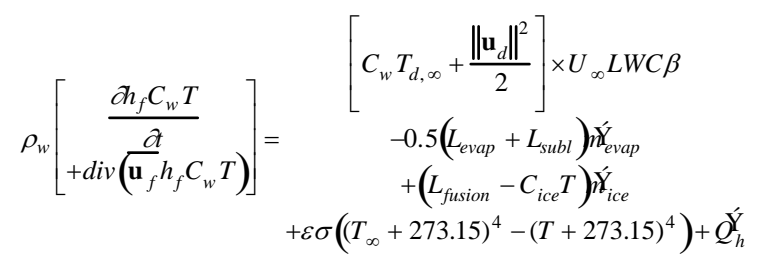

where the first three terms on the right-hand-side model, respectively, the heat transfer caused by the supercooled water droplets impinging on the surface, and that from evaporation and ice accretion. The last two terms in the equation represent the radiative and convective heat transfer.

The convective heat transfer is obtained from the CFD code, by imposing a constant clean airfoil surface temperature above the free-stream temperature . The heat flux is converted into a heat transfer coefficient, before ice accretion calculations, because the heat transfer coefficient depends only weakly on the surface temperature distribution [20].

The coefficients $\rho_{w}, C_{w}, C_{\text {ice }}, L_{\text {evap }}, L_{\text {subl }}, L_{\text {fusion }}$ represent physical properties of water, while $T_{d, \infty}, U_{\infty}, L W C$, and $T_{\infty}$ are airflow and droplet parameters specified by the user. The ambient icing conditions completely determine those values. The temperatures are in Celsius.

The Eulerian droplet module provides local values for the collection efficiency $\beta$ and the droplet impact velocity $\mathbf{u}_{d}$. The flow solver provides the local wall shear stress $\tau_{\text {wall }}$ and the convective heat flux $\mathcal{Q}_{h}$. The evaporative mass flux is recovered from the convective heat flux using a parametric model [5]. There remain three unknowns: the film thickness $h_{f}$, the equilibrium temperature $T$ within the air/water film/ice/wall interface, and the instantaneous mass accumulation of ice $m_{\text {ice }}$. Compatibility relations are needed to close the system and one way to write them is the following:

$$
\begin{gathered}
h_{f} \geq 0 \\
\dot{m}_{\text {ice }} \geq 0 \\
h_{f} T \geq 0 \\
\dot{m}_{i c e} T \leq 0
\end{gathered}
$$




\section{Development of a Second Generation In-flight Icing Simulation Code}

The discretization of these equations is via FVM. The trace of the three-dimensional mesh at the air-structure/ice shape interface is called the surface mesh. From the surface mesh, a dual surface mesh is obtained by connecting the centroids of the surface mesh cells to the mid-edges of the cells. The unknowns are then computed at the center of each cell, corresponding one-to-one to the nodes of the FEM used for the air and droplet solutions.

After a given ice accretion time, the ice accretion solver returns a wall temperature distribution and the displacements of the surface nodes and. These displacements and temperature distribution can be used to calculate a new airflow solution and start a new calculation cycle. With a Navier-Stokes flow solver, for sufficiently large ice horns, separation may occur. This separation will affect the overall flow field and the local heat transfer coefficient. Although actual turbulence models are not very accurate for separated flows, they still represent a significant improvement on a viscous/non-viscous coupling method. Knowing that first generation codes fail to predict this separation, it can thus be expected that even for 2D glaze ice cases, discrepancies will exist between numerical results.

In the three dimensional cases, ice accretion results were obtained using only one cycle of calculation (one-shot ice accretion). Thus, effect of ice accretion on the airflow and droplets fields is neglected. It means loosing part of the advantage of using a NavierStokes solver. For the actual 3D test cases, this simplification is justified by the rime ice accretion conditions that produce ice shapes with relatively low impact on airflow for the rotor blade tip. This will have to be confirmed in the future by running multiple layers ice accretion.

To do multi layers ice accretion in 3D take a large computing time, and considering that for the nacelle only numerical results for one-shot ice accretion are available from the LEWICE code, in this article only one-shot results are shown for 3D calculations.

\section{TWO-DIMENSIONAL VALIDATIONS}

ICE3D has been compared to numerical solutions obtained with LEWICE, and experimental results obtained in the NASA Glenn Icing Research Tunnel (IRT) [21]. All 2D calculations are carried out in a pseudo-3D manner on meshes of one element thickness in the spanwise direction. A consensus [22, 23] about the comparison criteria of two icing shapes is difficult to obtain . Indeed, the focus can be on different criteria such as the limit of impact, the ice thickness or the location and angle of a possible horn, etc. As a consequence, the comparisons remain most of the time subjective but conservative enough to meet best aircraft safety. 
Development of a Second Generation In-flight Icing Simulation Code

\section{MESH DENSITY EFFECTS}

The effect, on the ice accretion simulation, of mesh density around the leading edge of a NACA 0012 airfoil has been studied with a coarse (90 mesh point on the airfoil), medium (180 mesh points) and fine grid (360 mesh points). The meshes contain, respectively, a total of 23,350, 36,130 and 61,690 nodes. The spacing in the direction normal to the wall is kept the same for the 3 meshes and is equal to $8.4 \times 10^{-6} c, c$ being the chord of the airfoil. The ambient conditions selected for this test case correspond to the LEWICE run 403[21] and are given in Table 1 . The accretion time is 7 minutes. The airflow, impingement and ice accretion solutions on the 3 meshes are compared to each other and compared to LEWICE solutions. For the airflow and impingement solutions the results are plotted against the distance from the stagnation point.

\begin{tabular}{|l|l|l|l|}
\hline \hline Parameter & Run 403 & Run 404 & Run 308 \\
\hline$T_{\infty}$ & $262.04 \mathrm{~K}$ & $256.49 \mathrm{~K}$ & $262.04 \mathrm{~K}$ \\
\hline$P_{\infty}$ & $100 \mathrm{kPa}$ & $90.76 \mathrm{kPa}$ & $90.76 \mathrm{kPa}$ \\
\hline$U_{\infty}$ & $102.8{\mathrm{~m} . \mathrm{s}^{-1}}$ & $102.8 \mathrm{~m} \cdot \mathrm{s}^{-1}$ & $102.8 \mathrm{~m} . \mathrm{s}^{-1}$ \\
\hline$A O A$ & $4^{0}$ & $4^{0}$ & $4^{0}$ \\
\hline$M V D$ & $20 \mu \mathrm{m}$ & $20 \mu \mathrm{m}$ & $20 \mu \mathrm{m}$ \\
\hline$L W C$ & $0.55 \mathrm{~g} / \mathrm{m}^{3}$ & $0.55 \mathrm{~g} / \mathrm{m}^{3}$ & $1 \mathrm{~g} / \mathrm{m}^{3}$ \\
\hline $\operatorname{Re}_{\infty}$ & $4.39 \times 10^{6}$ & $4.14 \times 10^{6}$ & $4.14 \times 10^{6}$ \\
\hline \hline
\end{tabular}

Table 1: Ambient conditions corresponding to 2D test cases.

\section{Airflow solution}

The turbulence model selected for the simulation is the one-equation Spalart-Allmaras model with an equivalent sandgrain roughness of $0.55 \mathrm{~mm}$. The grid study shows that the solutions on the medium and fine grids are similar and appear to be meshindependent, as far as the heat transfer coefficient is concerned.

LEWICE uses an integral method to solve the boundary layer. LEWICE and FENSAP solutions are compared in Fig. 2. The differences between the two curves close to the trailing edge are due to the boundary layer thickness , not taken into account in the LEWICE code. Close to transition points the differences are most probably induced by the turbulence model. The equivalent 
Development of a Second Generation In-flight Icing Simulation Code

sandgrain roughness coefficient used for this calculation is the same as in LEWICE. This roughness coefficient is especially calibrated for LEWICE. Although the two turbulence models employed are strongly different, the two solutions agree pretty much and the results are satisfactory.

\section{Impingement solution}

The local collection efficiency curves are identical for the three meshes, thus droplet solutions appear to be mesh-independent.

The comparison with LEWICE is shown in Fig. 3. The maximum collection efficiency predicted by the two codes is identical. The impingement limits are slightly different on the upper part of the airfoil ( $s \geq 0$ ). This is most probably due to a small difference in flow fields. LEWICE solves for a potential flow and the angle of attack is lowered from $4^{\circ}$ to $3.5^{\circ}$ to match the overall lift coefficient. For the Navier-Stokes numerical solution, a free stream angle of attack of $4^{\circ}$ is used.

\section{Ice accretion solution}

For the ice accretion module, a one-shot ice accretion simulation is performed on each mesh. The aim is to have larger ice shapes to compare, and also not to mix the effect of mesh density with the effect of airflow solution updates on the solution. Beaugendre [14] has studied this last aspect.

The comparison of ice shapes on the three meshes shows not much difference, and only results on the finer mesh are shown. The mass of ice accreted is the same for the three meshes and is equal to $0.496 \mathrm{~kg}$ per unit span.

For this run, two experimental solutions are available and plotted on Fig. 4. The LEWICE numerical solutions obtained with a multi-stepping approach composed of 7 layers is also available and shown. The one-shot ICE3D shape is acceptable compared to the experimental and numerical solutions, especially if we take into account the fact that the overpredicted ice thickness on top of the airfoil will substantially decrease if a multi-stepping approach were used. Indeed, this part of the airfoil will be in the shadow zone of the bump located between the coordinates: $0<\mathrm{Y}<0.2$ in.

\section{VALIDATION ON AIRFOIL: NACA 0012}

The NACA 0012 airfoil has been used in several test entries. The data from this airfoil represent the highest number of ice shapes that have been created in the IRT. Through all this section, the ice shapes are plotted in inches. 
Development of a Second Generation In-flight Icing Simulation Code

\section{Run 404}

In the first comparison, ice is accreted for 7 minutes on a NACA 0012 airfoil at $4^{\circ}$ angle of attack. The ambient icing conditions, which should be close to rime ice accretion are given in Table 1 and correspond to LEWICE Run 404 [21].

Figure 5 shows the final ice shape computed by LEWICE and ICE3D, compared to the experimental ice shape obtained in the IRT. The limits of impact are identical for LEWICE and ICE3D and match the experiments on the suction side of the airfoil, but are under predicted by both codes on the pressure side of the airfoil. ICE3D's ice shape is thicker and closer to the experimental ice shape than LEWICE on the upper part of the airfoil. This may be due to a larger estimation of the water evaporation by LEWICE. ICE3D also predicts a slightly smaller ice thickness on the pressure side, where the LEWICE solution is closer to the measurement.

\section{Run 308}

In the second comparison, ice is accreted on a NACA 0012 airfoil at $4^{\circ}$ angle of attack for 231 seconds. The ambient conditions, closer to glaze ice conditions, are summarized in Table 1 and correspond to LEWICE Run 308[21].

Figure 6 shows the comparison between LEWICE and ICE3D numerical solutions after 47.58 and 95.16 seconds of accretion. At 47.58 seconds of accretion, ICE3D and LEWICE solutions are identical: same ice thickness and limits of impact for both codes. After 95.16 seconds of accretion, LEWICE and ICE3D solutions remain very close to each other, LEWICE predicting a slightly bigger amount of runback than ICE3D. Both codes predict the formation of a horn on the upper part of the NACA 0012 airfoil, with the same angle and ice thickness.

After 95.16 seconds of accretion, the horn predicted by ICE3D induces a separation in the flow solution. Contrary to LEWICE, which may be able to predict but not compute separation with only a viscous/inviscid interaction, ICE3D’s convective heat transfer coefficient and shear stress decrease suddenly in the separation area. As a consequence, impact may be predicted behind a horn as can be seen in Fig. 7. ICE3D's final ice shape is very close to LEWICE's, but both codes fail to predict the horn's angle of the experimental ice shape. There is still room for improvement in the quality of ice-accretion-shape predictions yielded by current icing codes, as large differences between predicted and experimental ice shapes are often encountered [23] in glaze ice conditions, compounded by the problem of the lack of consistency of ice shapes produced in icing wind tunnels. 
Development of a Second Generation In-flight Icing Simulation Code

\section{D HELCOPTER ROTOR BLADE TIP RESULTS}

The first test case considered is a three-dimensional helicopter rotor blade tip. This case was selected because of the availability of experimental and numerical results. Its three-dimensional effects are small, and a quasi-three dimensional model that accretes ice along the flow streamlines from ONERA calculated a numerical solution [4] to compare to.

This three-dimensional helicopter rotor tip geometry is rather briefly described in paper [4] as follows:

“...from the base to the top along the span, the chord varies from 0.6 to $0.2 \mathrm{~m}$, the leading edge sweep angle starts at 0 and ends at

\begin{tabular}{|c|c|}
\hline \hline Parameter & Value \\
\hline \hline$T_{\infty}$ & $-30.5^{\circ} \mathrm{C}$ \\
\hline$P_{\infty}$ & $456 \mathrm{hPa}$ \\
\hline Mach & 0.52 \\
\hline AOA & $9.5^{\circ}$ \\
\hline MVD & $20 \mu \mathrm{m}$ \\
\hline LWC & $1 \mathrm{~g} / \mathrm{m}^{3}$ \\
\hline time & $91 \mathrm{~s}$ \\
\hline \hline
\end{tabular}

Table 2: Ambient conditions for the helicopter rotor blade tip simulation

$60 \mathrm{deg}$. The trailing edge is perpendicular to the flow and is lightly spun so that the incidence angle at the top is 0.74 deg less than at the base. The span is $0.48 \mathrm{~m}$. The rotor blade tip is built from a NACA 13106 airfoil.”

Based on this short description, a Computer Aided Design (CAD) of the geometry was produced with the ICEM DDN software. The one-equation Spalart-Allmaras model was used for turbulence modeling and mesh adaptation was carried out with OptiMesh [24], an anisotropic (highly directional and highly stretched) automatic mesh adaptation code. Unfortunately, it turns out that the experimental model does not follow exactly the description given in paper [4].

\section{AIRFLOW SOLUTION AND MESH ADAPTATION}

The conditions for the simulation are shown in Table 2. 


\section{Development of a Second Generation In-flight Icing Simulation Code}

To improve the quality of the flow solution, three mesh adaptations cycles were carried out with OptiMesh. The OptiMesh algorithm has an a-posteriori error estimate based on the Hessian of the solution (hence proportional to the truncation error) and then uses mesh movement, edge refinement, coarsening and swapping to automatically yield a nearly-optimal adapted grid. These actions are done throughout the numerical solution and the grid edges migrate where the flow phenomena mandate. OptiMesh has proven to asymptotically get to a unique final grid [25], no matter what the initial grid is like and yields results independent of the code used. The initial mesh has 221,800 nodes and 1,118,131 elements, and the final adapted one has 467,705 nodes and 2,546,857 elements.

The GCI method suggested by Roache [26] for unstructured grid refinement based on the number of nodes is used to get an idea of the accuracy of the pressure coefficient distribution on the wing. Accuracy of the Cp distribution at the four stations defined below is conservatively estimated around 4\%. Although this error seems large, it was judged acceptable considering that the goal is to predict ice shape using a one-shot ice accretion, thus neglecting effects of the ice growth on the airflow and droplet solutions.

An equivalent sandgrain roughness was used for the icing calculations and it is obtained using an empirical correlation given in [3], and corresponds to $0.269 \mathrm{~mm}$ in this case.

To help the discussion of the results, 2D cuts at four different spanwise locations are performed. Each cut corresponds to a plane $(\mathrm{x}, \mathrm{z}$ ), and the cuts are referred to as station 1 (location $\mathrm{y}=0.09 \mathrm{~m}$.), station 2 (location $\mathrm{y}=0.25 \mathrm{~m}$.), station 3 ( $\mathrm{y}=0.30 \mathrm{~m}$.) and station 4 $(y=0.45 \mathrm{~m}$.). The origin of the coordinate system is at the root of the wing at the leading edge. The $y$-axis is in the spanwise direction, and the $\mathrm{x}$-axis is the curvilinear distance along the surface in the chord wise direction. Positive values for x-axis are above the plane $\mathrm{y}=0$, and negative value below. The chord at the root of the wing, namely $0.586 \mathrm{~m}$, scales the curvilinear distance.

As presented in Fig. 8, the finite blade modeled in this article engenders 3D aerodynamic effects; first, with the creation of a local aerodynamic angle of attack different from the free stream and, second, with the creation of a tip vortex at the blade extremity. Due to a negative twist angle, a separation bubble appears in that region. All aerodynamic variables are affected by this flow pattern.

Figure 9 shows the convective heat transfer coefficient for stations 1, 2, 3 and 4 . The heat transfer coefficient curves are quite similar along the blade, except close to the tip, station 4 , where the vortex induces separation. At this station, the heat transfer coefficient decreases rapidly on the upper side of the wing, before increasing abruptly at the reattachment point. In a separation bubble, heat transfer coefficients are expected to be small. 
Development of a Second Generation In-flight Icing Simulation Code

\section{COLLECTION EFFICIENCY DISTRIBUTION}

In Fig. 10, the coordinates along airfoil section corresponding to each station are divided, using the root chord length, to make comparison easier. Keeping in mind that the wing section reduces in size from the root to the tip, even if the impingement limits on the lower side are almost constant, they extend further back on the airfoil closer to the tip. On the other hand, the impingement limit on the upper side of the blade decreases from station 1 to station 4 . This effect is due to the negative twist angle.

\section{ICE ACCRETION}

Once the FENSAP airflow solution and the collection efficiency from DROP3D have been determined, ice accretion can be performed, using ICE3D, on the adapted grid. The 91-second exposure has been simulated in one shot. Figure 11 gives a 3D view of the rime ice accretion at tip.

Two-dimensional cuts of the ice shape corresponding to stations 1, 2, 3 and 4 are plotted in figure 12 . The global aspect of the ice shape qualitatively agrees with the numerical and experimental results of ONERA [4], keeping in mind that the ONERA results were obtained on a slightly different geometry. The 3D effects are not spectacular, as the geometry does not present strong 3D features and the very cold temperature corresponds to rime ice conditions, making water runback not an important factor. In fact, the ice shape mostly depends on impingement, and this is a good test case to ascertain values calculated by DROP3D.

\section{D NON-AXISYMMETRIC NACELLE}

In this calculation the aim is to predict ice accretion on a 3D non-axisymmetric Boeing 737-300 [27] nacelle inlet. A complete set of computational and experimental results, made by NASA [28], are available for the airflow solution and the collection efficiency, but not for the ice shapes. Thus, the only thing that one can do is compare ICE3D's predictions to LEWICE's.

The icing calculation process requires three steps: the computation of the airflow, the computation of the droplet solution and the prediction of the ice shape. Each "step solution" will be compared to the corresponding LEWICE solution and to the experiments, if available.

Two cases were analyzed at a true airspeed of $75 \mathrm{~m} / \mathrm{s}$, an inlet mass flow of $10.4 \mathrm{~kg} / \mathrm{s}$, a static pressure of 95840 Pa, a droplet Mean Volumetric Diameter of $20.36 \mu \mathrm{m}$, and nacelle incidences of $0^{\circ}$ (run id 092385-1,2,3-737-0 in Ref. [27]) and 15 (run id 092385-13,14,15-737-15 in Ref. [27]). 3D rime ice accretion result is shown on Fig. 13 for the $15^{\circ}$ case. 


\section{Development of a Second Generation In-flight Icing Simulation Code}

Tran et al. [29] used OptiMesh and compared Mach number distributions along circumferential cuts, for both incidences. The starting mesh had 108000 nodes and 624000 tetrahedra. After two adaptation cycles, the mesh size increased to 152000 nodes and 824000 highly anisotropic tetrahedral elements. The calculated Mach number distributions are in good agreement with both experimental and LEWICE results for all circumferential positions, at both incidences. A sample of results, post-processed to be in the same units of those of Ref. [14], is shown on Fig. 14 and Fig. 15.

In order to compute the local catch efficiency $\beta$, DROP3D was run for a Langmuir-D droplet distribution. The comparison of local catch efficiency distribution along the same circumferential cuts is presented in the same article (Ref. [15]). The peak is shown to be within experimental repeatability, estimated in Ref. [13] to be between 0.20 and 0.25 . The results show that, while FENSAP-ICE and LEWICE catch efficiency results agree over most of the nacelle. However, the impingement limits predicted by FENSAP-ICE are somewhat closer to the experimental values, as it uses a CFD (field) approach that has no difficulties near boundaries. Figures 16 and 17 present selected comparisons between DROP3D, LEWICE and the experiments.

Two icing conditions were calculated for each incidence of the Boeing 737-300 inlet. The conditions were chosen to represent a rime and a glaze ice situation. The rime conditions are the following: an accretion time of 30 minutes with a $\mathrm{LWC}$ of $0.2 \mathrm{~g} / \mathrm{m}^{3}$ and a static temperature of $-29.9^{\circ} \mathrm{C}$. For the mixed or glaze ice conditions, the time of exposure is still 30 minutes but the LWC is 0.695 $\mathrm{g} / \mathrm{m}^{3}$ and the static temperature is $-9.3^{\circ} \mathrm{C}$.

In the rime ice case, the comparison between LEWICE and ICE3D is very good for all circumferential positions for both incidences, Fig. 18 and Fig. 19.

For the glaze ice condition, the LEWICE and ICE3D predicted ice shapes, Fig. 20 and Fig. 21, agree pretty well for all circumferential positions and for both incidences.

Although no experimental data was available, it is comforting that the results obtained by the two codes are in good agreement and look consistent with the conditions for which the shapes were generated and with the airflow and droplet solutions. 
Development of a Second Generation In-flight Icing Simulation Code

\section{CONCLUSIONS}

A second-generation numerical approach based on partial differential equations has been proposed for calculating all aspects of inflight icing on complete aircraft. FENSAP-ICE, a code based on the proposed method, has been used to calculate ice shapes on 2D airfoils and 3D aircraft parts. Comparisons against 2D experimental and numerical results available in the literature show that the FENSAP-ICE code give results as accurate as first generation icing codes. Now that the numerical scheme has been shown to work, more tests will have to be carried out in order to test the limits of the physical model used. For example, capability of the turbulence model to predict correctly the separated area behind an ice horn will have to be verified. Also, the effect of the separation area on the growing ice shape is not yet clear. The main strength of the new method compared to first generation icing codes, apart from the 3D ice prediction capability, is the possibility to use advances from other computational fluid dynamic areas where PDEs are used.

Apart from the modeling inaccuracies related to the turbulence model on rough surfaces and in separated areas, there are other possible sources of numerical error: mesh related error during solution and error on collection efficiency coefficients due to the lack of updating of the air solution. Using mesh adaptation based on airflow solution and geometry reduces the first error. Tight coupling between the three modules must be achieved, with thin layers of ice accretion before airflow recalculation, to reduce the second error. Although this article does not show such results, this is currently achieved through the use of an efficient mesh displacement scheme.

Successful 3D calculations around slightly complex geometries have shown the capability of a second-generation CFD-based inflight icing simulation system. Calculation around a 3D rotor blade tip has shown the capability of the code to calculate the flow field, droplet impingement and ice accretion all on the same mesh. A complete 3D ice accretion prediction on a Boeing 737-300 nacelle, whose flow solution and droplet impingement have already been successfully completed, has also been demonstrated. The code is now being used to tackle even more complex problems such as wing body junctions and high-lift wings.

\section{NOMENCLATURE}

\section{Airflow variables}

AOA Aerodynamic angle of attack

h Heat transfer coefficient

L Characteristic length 
Development of a Second Generation In-flight Icing Simulation Code

$\begin{array}{ll}P_{\infty} & \text { Pressure } \\ \mathrm{Y}_{\mathrm{h}} & \text { Convective heat flux } \\ \mathrm{T}_{\infty} & \text { Temperature at infinity in Kelvin } \\ \mathbf{u}_{\mathrm{a}} & \text { Air velocity } \\ \mathrm{U}_{\infty} & \text { Velocity at infinity } \\ \rho_{a} & \text { Air density } \\ \tau_{\text {wall }} & \text { Air wall shear stress tensor } \\ v & \text { Laminar dynamic viscosity } \\ & \end{array}$

Droplet variables

d Droplet diameter

Fr $\quad$ Froude number $\left(U_{\infty} / \sqrt{L g_{0}}\right)$

$\mathrm{g}_{0} \quad$ Magnitude of the gravity vector

g Gravity vector

K Droplet inertia parameter $\left(\rho_{w} d^{2} U_{\infty} / 18 L \mu_{w}\right)$

LWC Liquid Water Content

$\operatorname{Re}_{\mathrm{d}} \quad$ Droplet Reynolds number $\left(d U_{\infty}\left(\mathbf{u}_{a}-\mathbf{u}_{d}\right) / v\right)$ 
Development of a Second Generation In-flight Icing Simulation Code

$\begin{array}{ll}\tilde{\mathrm{T}}_{\mathrm{d}, \infty} & \text { Droplets temperature at infinity in Celsius } \\ \mathbf{u}_{\mathrm{d}} & \text { Droplets velocity } \\ \alpha & \text { Water volume fraction } \\ \beta & \text { Collection efficiency }\end{array}$

Water, ice variables

$C_{p} \quad$ Pressure coefficient

$\mathrm{C}_{\text {ice } \quad \text { Specific heat for ice }}$

$\mathrm{C}_{\mathrm{w}} \quad$ Specific heat for water

$\mathrm{h}_{\mathrm{f}} \quad$ Film thickness

Mire $_{\text {ice }} \quad$ Instantaneous mass of ice accretion

$\mathrm{m}_{\text {evap }} \quad$ Instantaneous mass of evaporation

$\mathrm{L}_{\text {evap } \quad \text { Latent heat of evaporation }}$

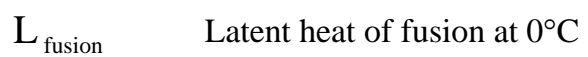

$\mathrm{L}_{\text {subl } \quad \text { Latent heat of sublimation }}$

T Temperature at wall / air / liquid-water / ice interface in Kelvin

t Time 
Development of a Second Generation In-flight Icing Simulation Code

$\begin{array}{ll}\mathbf{u}_{\mathbf{f}}, \overline{\mathbf{u}}_{\mathbf{f}} & \text { Film velocity vector and mean film velocity across the thickness } \\ \varepsilon & \text { Solid emissivity } \\ \sigma & \text { Boltzman constant } \\ \mu_{\mathrm{w}} & \text { Dynamic viscosity of water } \\ \rho_{\mathrm{w}} & \text { Water density }\end{array}$

Geometric variables

S curvilinear distance from stagnation point

$\mathbf{x}=\left(\mathrm{x}_{1}, \mathrm{x}_{2}\right)$ Coordinate along the wall

$\mathrm{y} \quad$ Coordinate normal to the wall

X Rotor blade tip chordwise direction

Y Rotor blade tip spanwise direction

Z Normal direction to the plane $(\mathrm{X}, \mathrm{Y})$ 
Development of a Second Generation In-flight Icing Simulation Code

Figure 1: Module interactions within FENSAP-ICE

Figure 2: Convective heat transfer coefficient distribution against the distance from stagnation point

Figure 3: Local collection efficiency distribution against the distance from stagnation point

Figure 4: Run 403 [NASA-CDROM], ice shape comparison between ICE3D (fine grid), LEWICE and experiments

Figure 5: Run 404 [NASA CD-ROM] comparison between LEWICE, and IRT experimental ice shape

Figure 6: Run 308 [NASA CD-ROM] comparison between ICE3D and LEWICE after 47.58 and 95.16 s of ice accretion

Figure 7: Run 308 [NASA CD-ROM] comparison between ICE3D, LEWICE and IRT experimental ice shape

Figure 8: Turbulent airflow solution, Mach number contours, streamlines at the tip and Cp distribution on the blade

Figure 9: 2D cuts of the convective heat transfer coefficient, in $\mathrm{W} / \mathrm{m}^{2} \mathrm{~K}$

Figure 10: 2D cuts of the collection efficiency for stations 1, 2, 3 and 4 along the curvilinear coordinate

Figure 11: 3D ice shape at blade tip

Figure 12: 2D ice cuts along the spanwise direction for stations 1, 2, 3 and 4

Figure 13: 3D ice accretion on the Boeing 737-300 inlet, rime ice accretion for $15^{\circ}$ AoA and an inlet mass flow of $10.4 \mathrm{~kg} / \mathrm{s}$

Figure 14: Mach number distribution for the Boeing 737-300 inlet for 0 deg AoA and an inlet mass flow of $10.4 \mathrm{~kg} / \mathrm{s}$, comparison between FENSAP, LEWICE and Experiments, circumferential cut 45 deg

Figure 15: Mach number distribution for the Boeing 737-300 inlet for 15 deg AoA and an inlet mass flow of 10.4 kg/s, comparison between FENSAP, LEWICE and Experiments, circumferential cut 45 deg

Figure 16: Local collection efficiency distribution for $0^{\circ}$ AoA, comparison between DROP3D, LEWICE and Experiments, circumferential cut $180 \mathrm{deg}$ 
Development of a Second Generation In-flight Icing Simulation Code

Figure 17: Local collection efficiency distribution for $15^{\circ}$ AoA, comparison between DROP3D, LEWICE and Experiments, circumferential cut 90 deg

Figure 18: Rime ice for the Boeing 737-300 inlet for $0^{\circ}$ AoA, comparison of analytical ice shapes between ICE3D \& LEWICE, circumferential cut 45 deg

Figure 19: Rime ice for the Boeing 737-300 inlet for $15^{\circ}$ AoA, comparison of analytical ice shapes between ICE3D \& LEWICE, circumferential cut 135 deg.

Figure 20: Glaze ice for the Boeing 737-300 inlet for $0^{\circ}$ AoA, comparison of analytical ice shapes between ICE3D \& LEWICE, circumferential cut 135 deg

Figure 21: Glaze ice for the Boeing 737-300 inlet for $15^{\circ}$ AoA, comparison of analytical ice shapes between ICE3D \& LEWICE, circumferential cut 45 deg 
Development of a Second Generation In-flight Icing Simulation Code

Figure 1: Module interactions within FENSAP-ICE

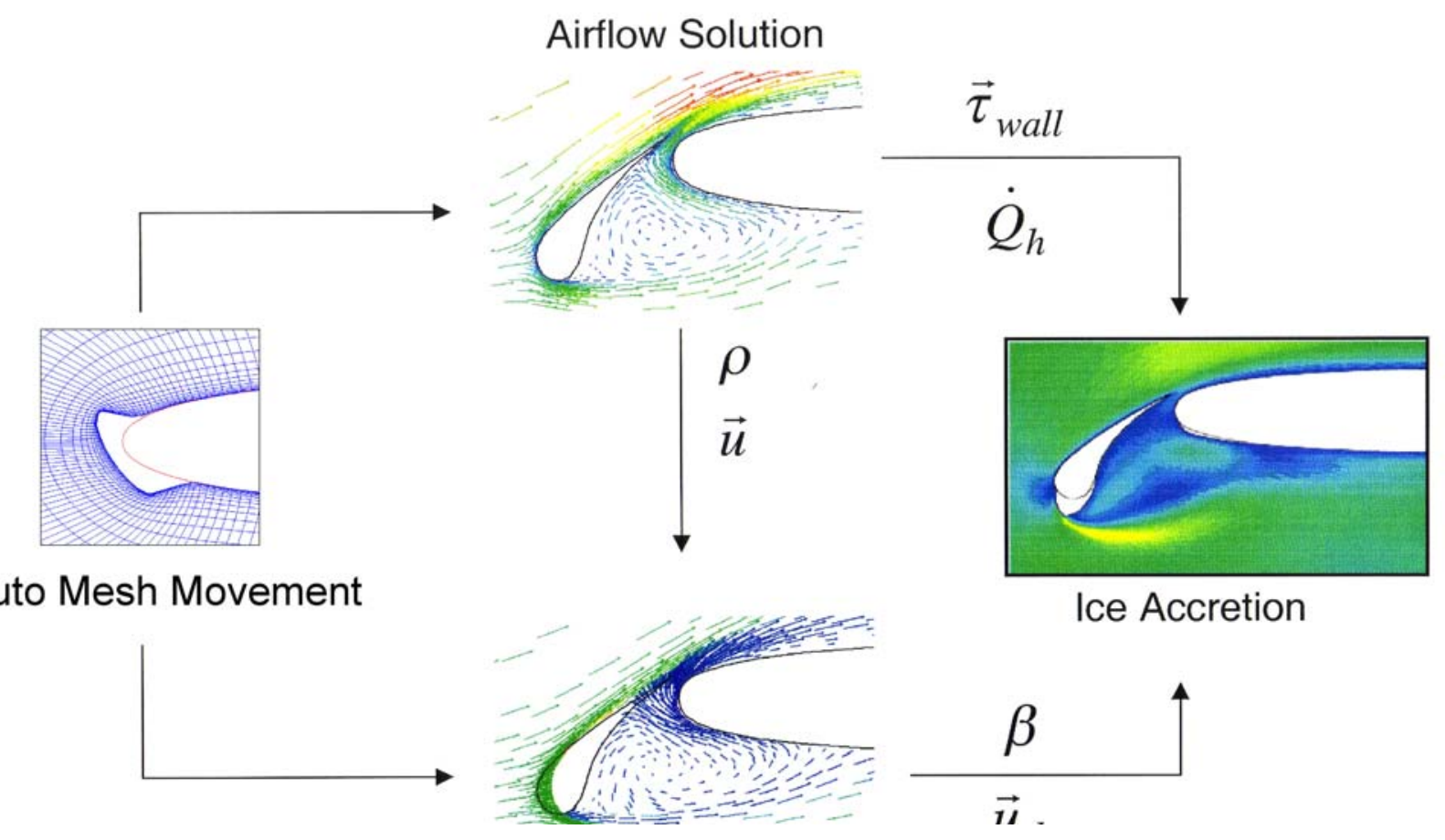


Development of a Second Generation In-flight Icing Simulation Code

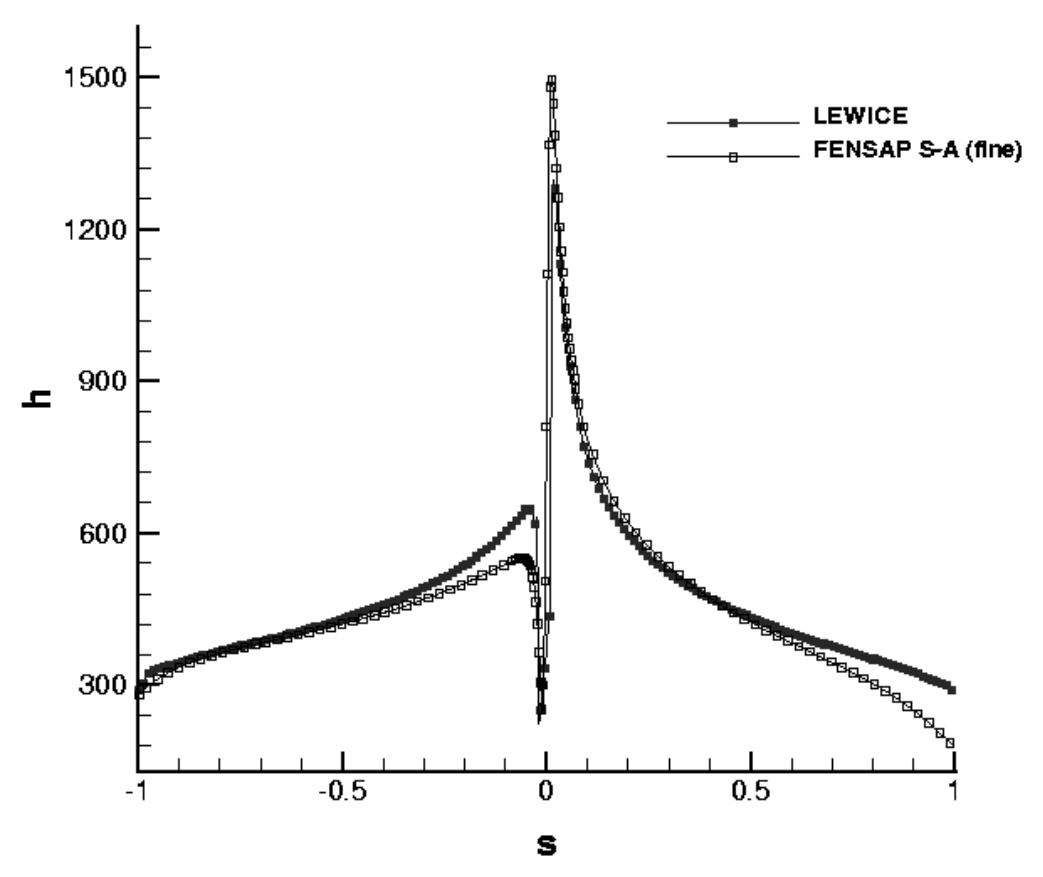

Figure 2: Convective heat transfer coefficient distribution against the distance from stagnation point 
Development of a Second Generation In-flight Icing Simulation Code

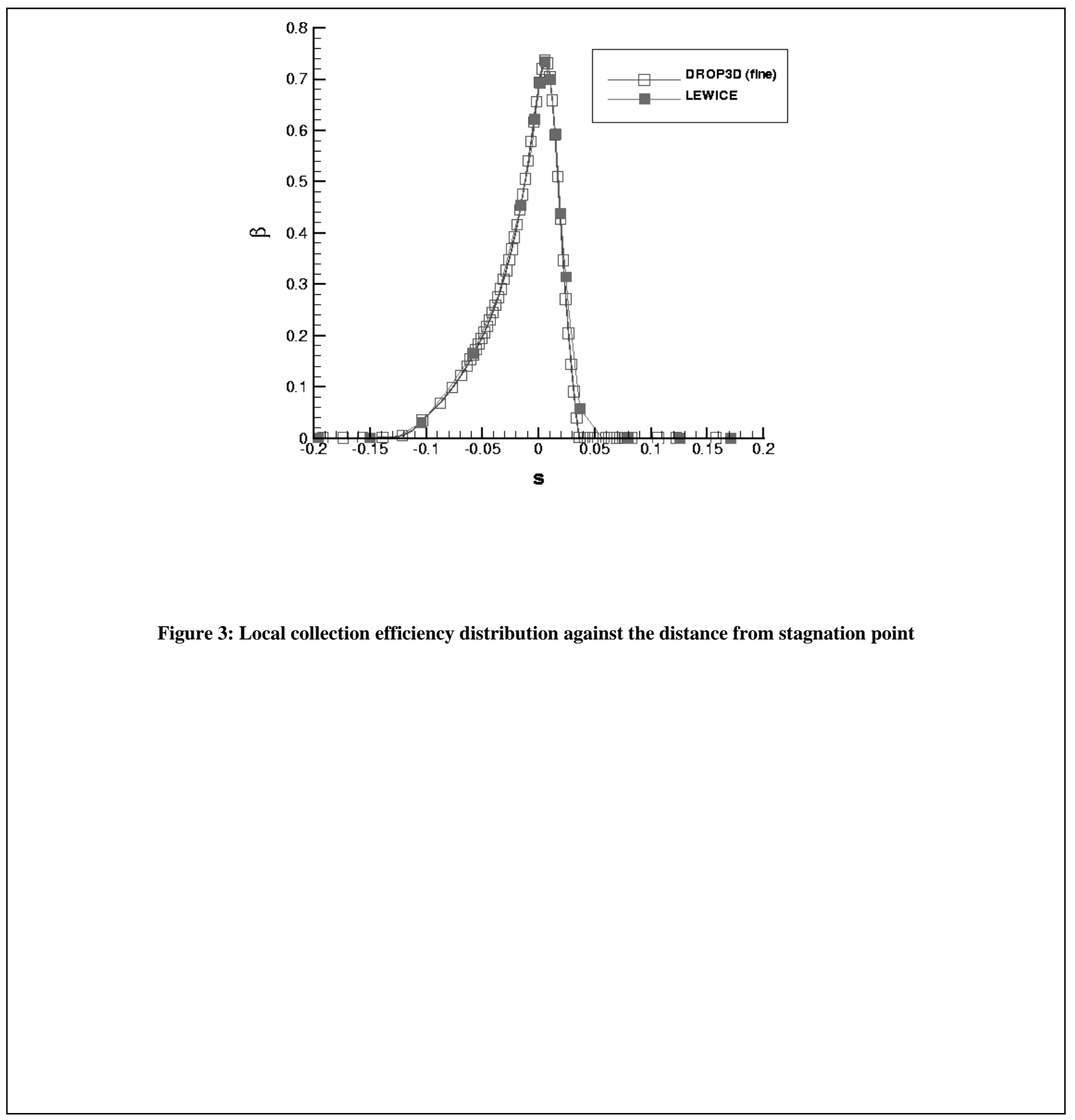


Development of a Second Generation In-flight Icing Simulation Code

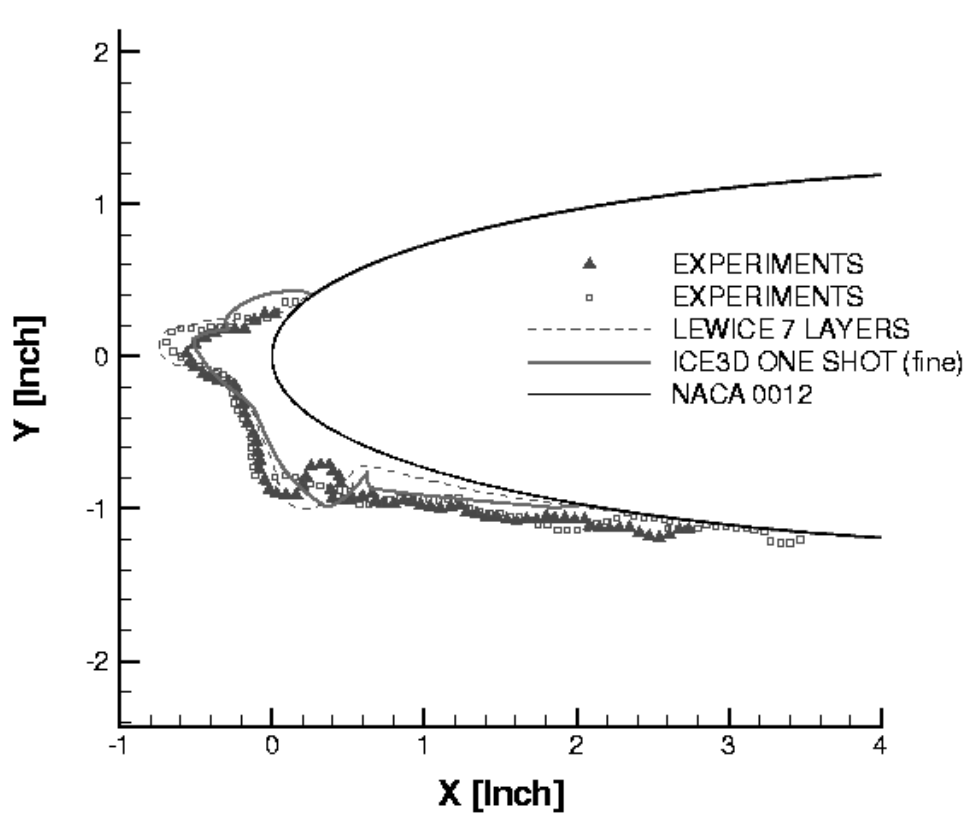

Figure 4: Run 403 [NASA-CDROM], ice shape comparison between ICE3D (fine grid), LEWICE and experiments 
Development of a Second Generation In-flight Icing Simulation Code

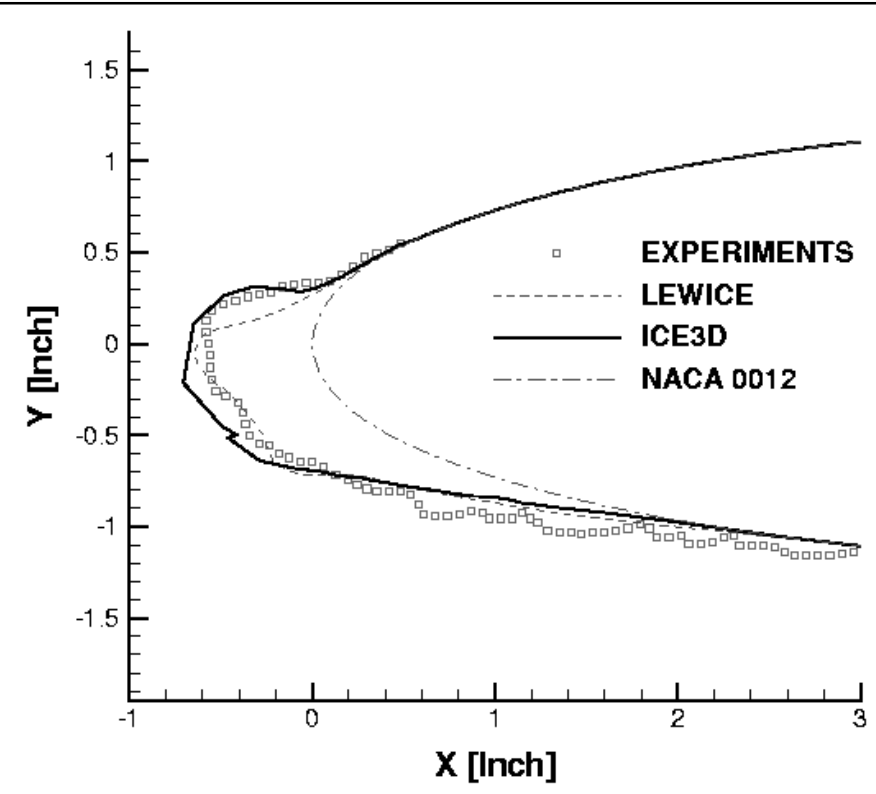

Figure 5: Run 404 [NASA CD-ROM] comparison between LEWICE, and IRT experimental ice shape 


\section{Development of a Second Generation In-flight Icing Simulation Code}

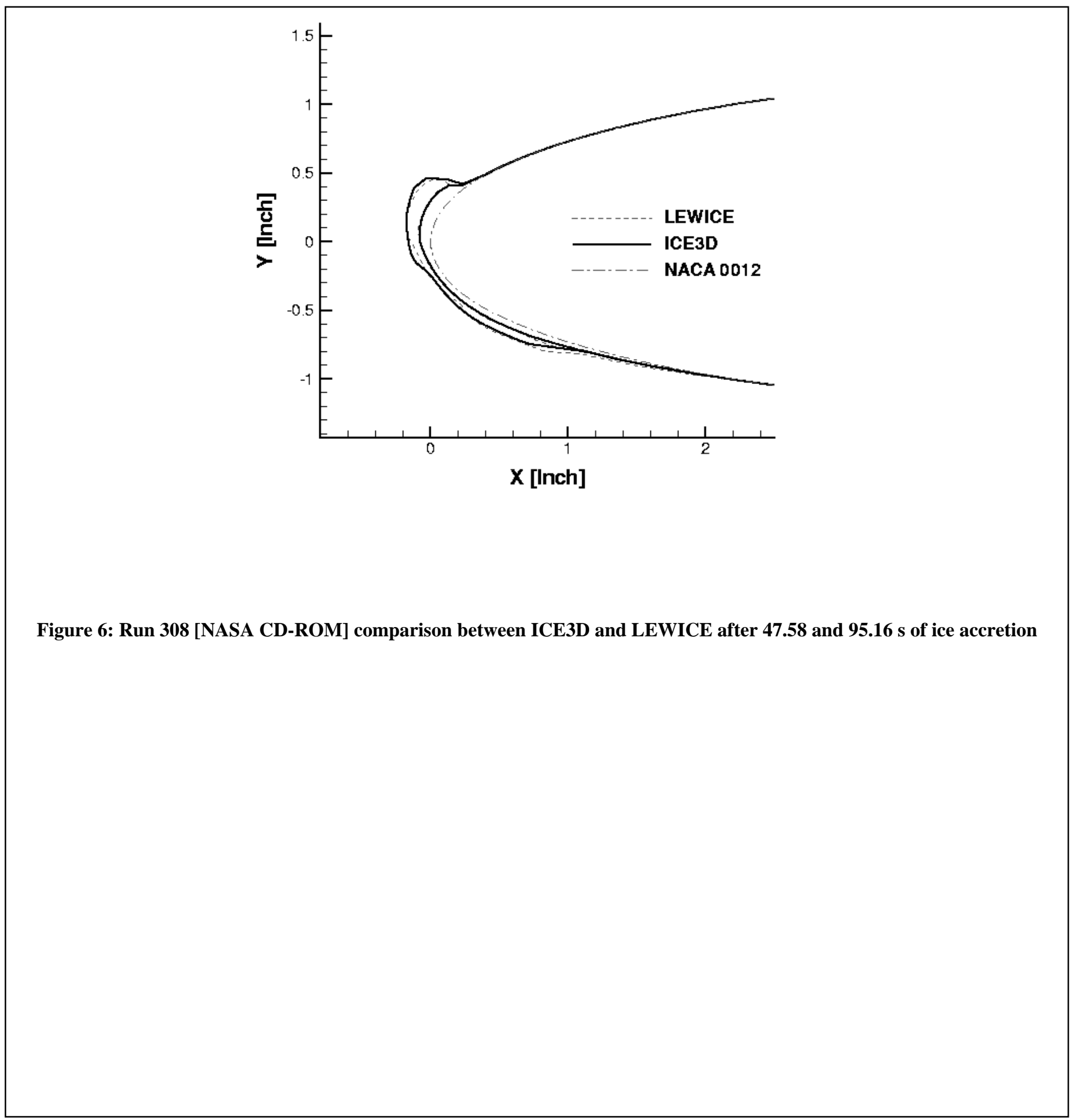


Development of a Second Generation In-flight Icing Simulation Code

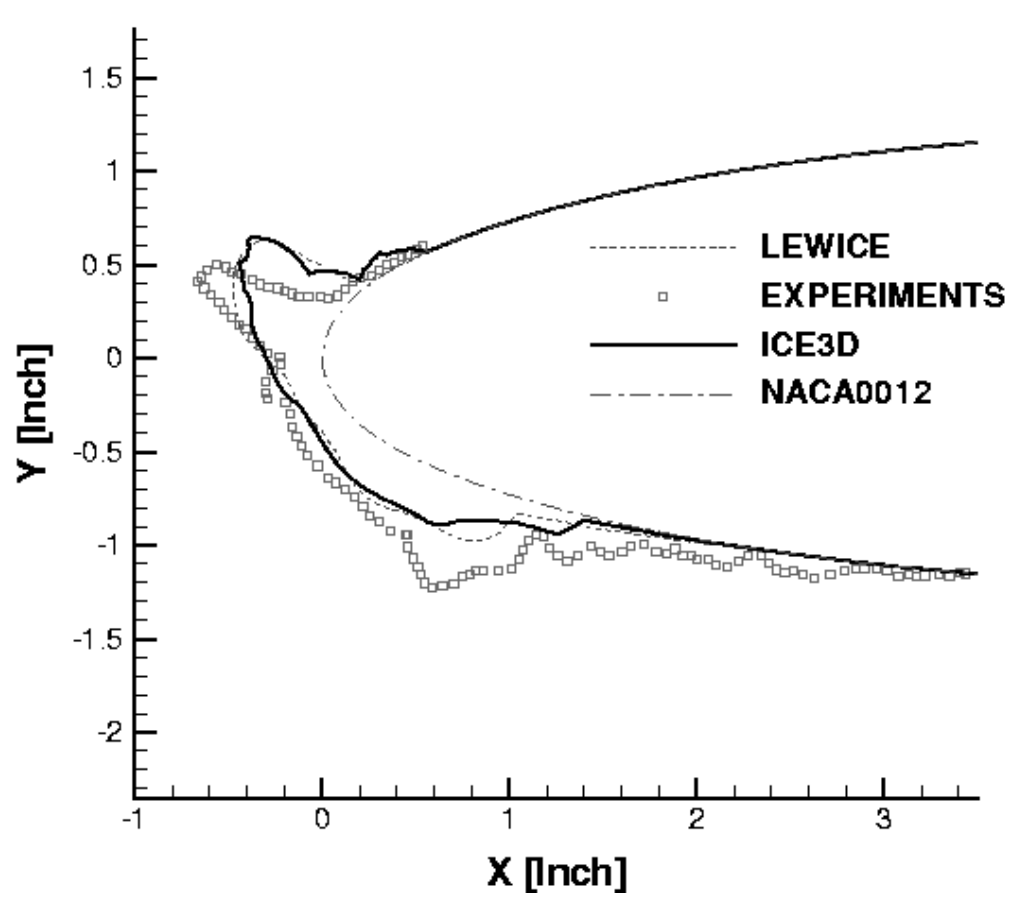

Figure 7: Run 308 [NASA CD-ROM] comparison between ICE3D, LEWICE and IRT experimental ice shape 
Development of a Second Generation In-flight Icing Simulation Code

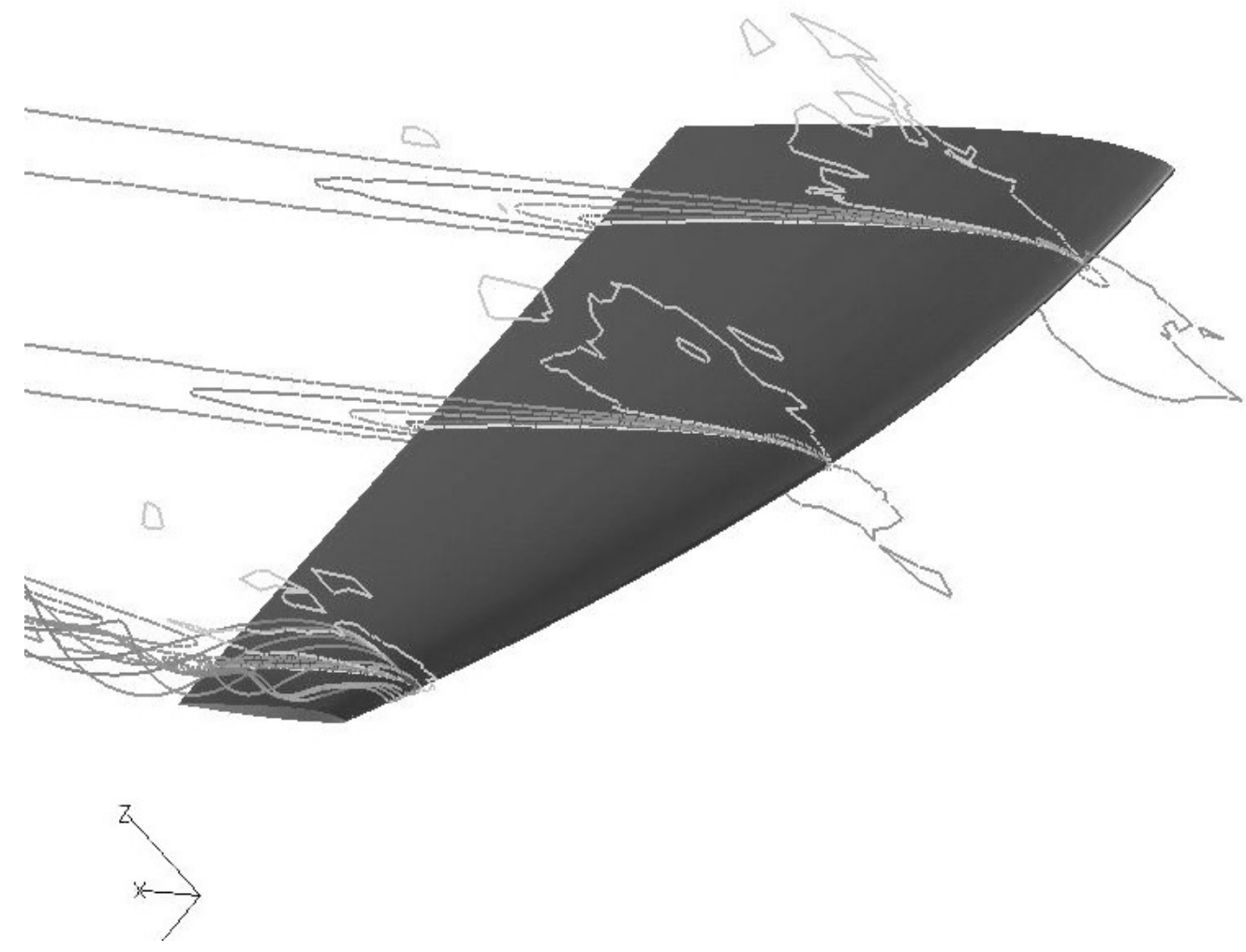

Figure 8: Turbulent airflow solution, Mach number contours, streamlines at the tip and Cp distribution on the blade 
Development of a Second Generation In-flight Icing Simulation Code

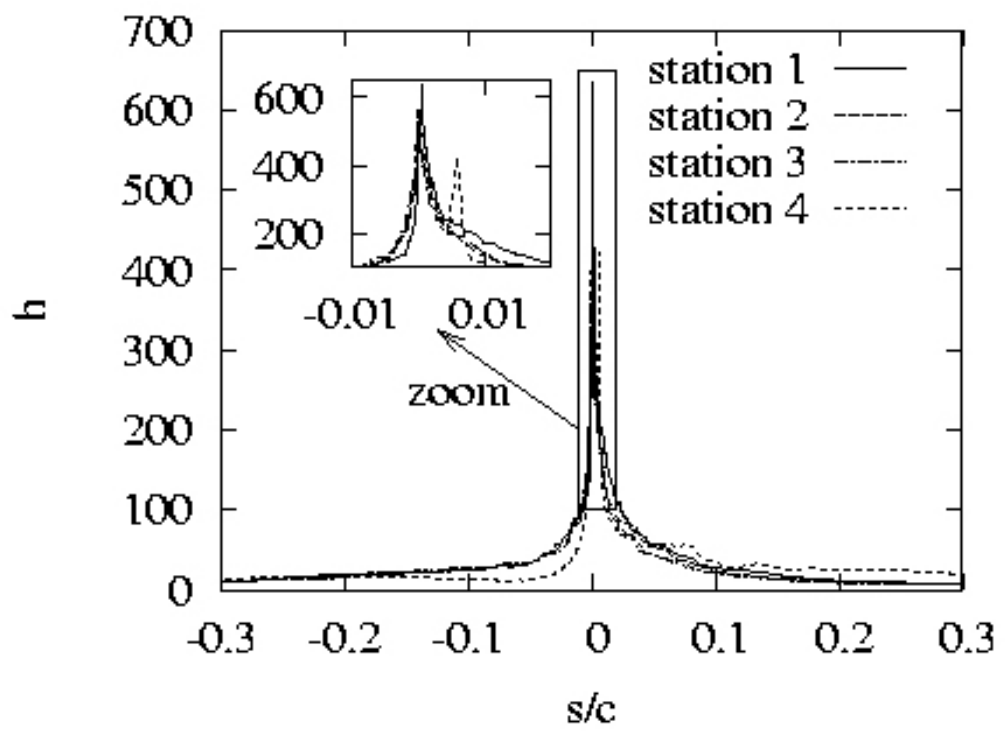

Figure 9: 2D cuts of the convective heat transfer coefficient, in $\mathrm{W} / \mathrm{m}^{2} \mathrm{~K}$ 
Development of a Second Generation In-flight Icing Simulation Code

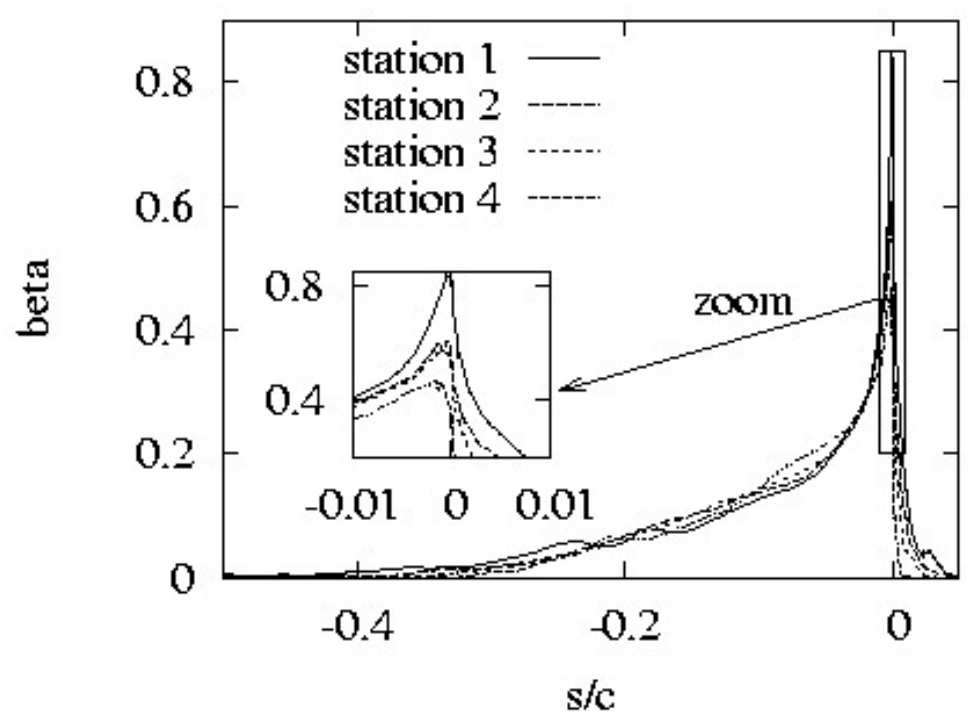

Figure 10: 2D cuts of the collection efficiency for stations 1, 2, 3 and 4 along the curvilinear coordinate 
Development of a Second Generation In-flight Icing Simulation Code

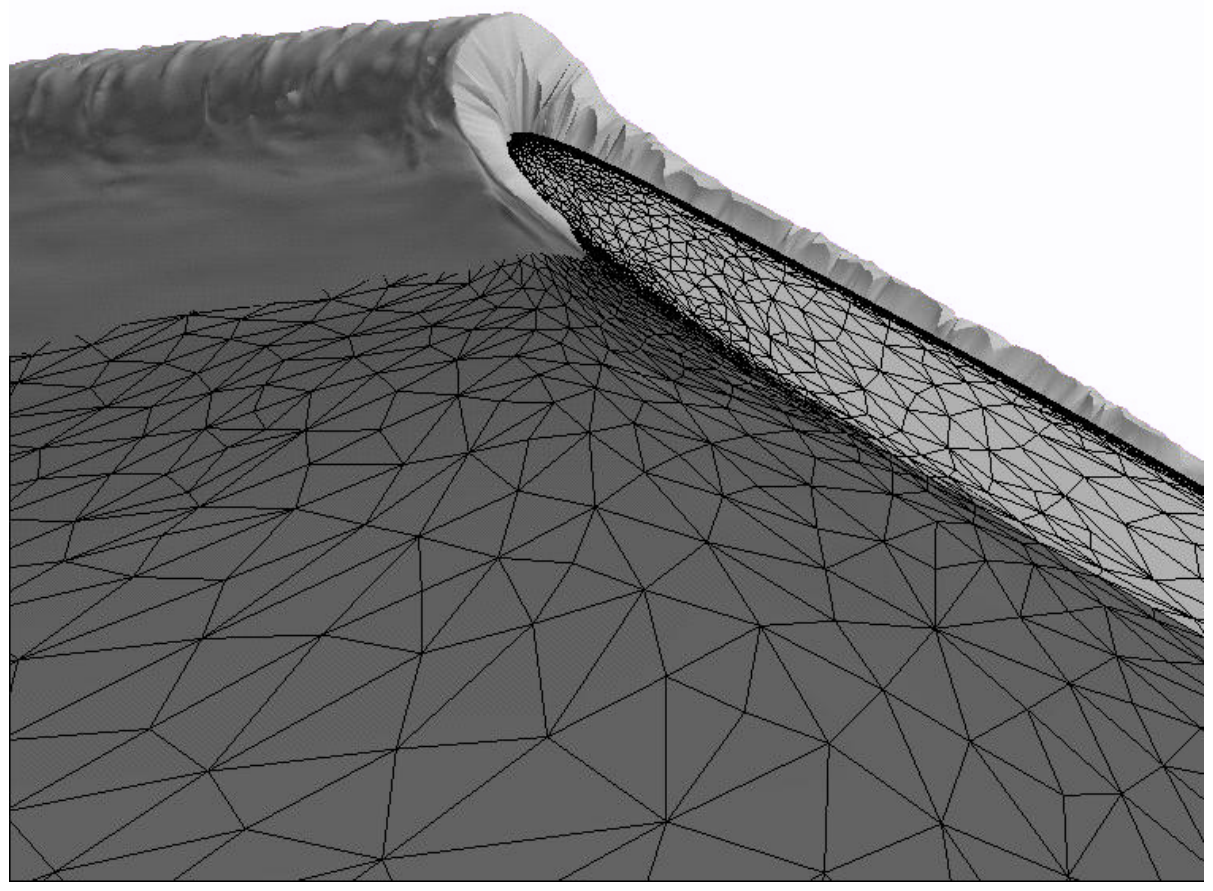

Figure 11: 3D ice shape at blade tip 
Development of a Second Generation In-flight Icing Simulation Code

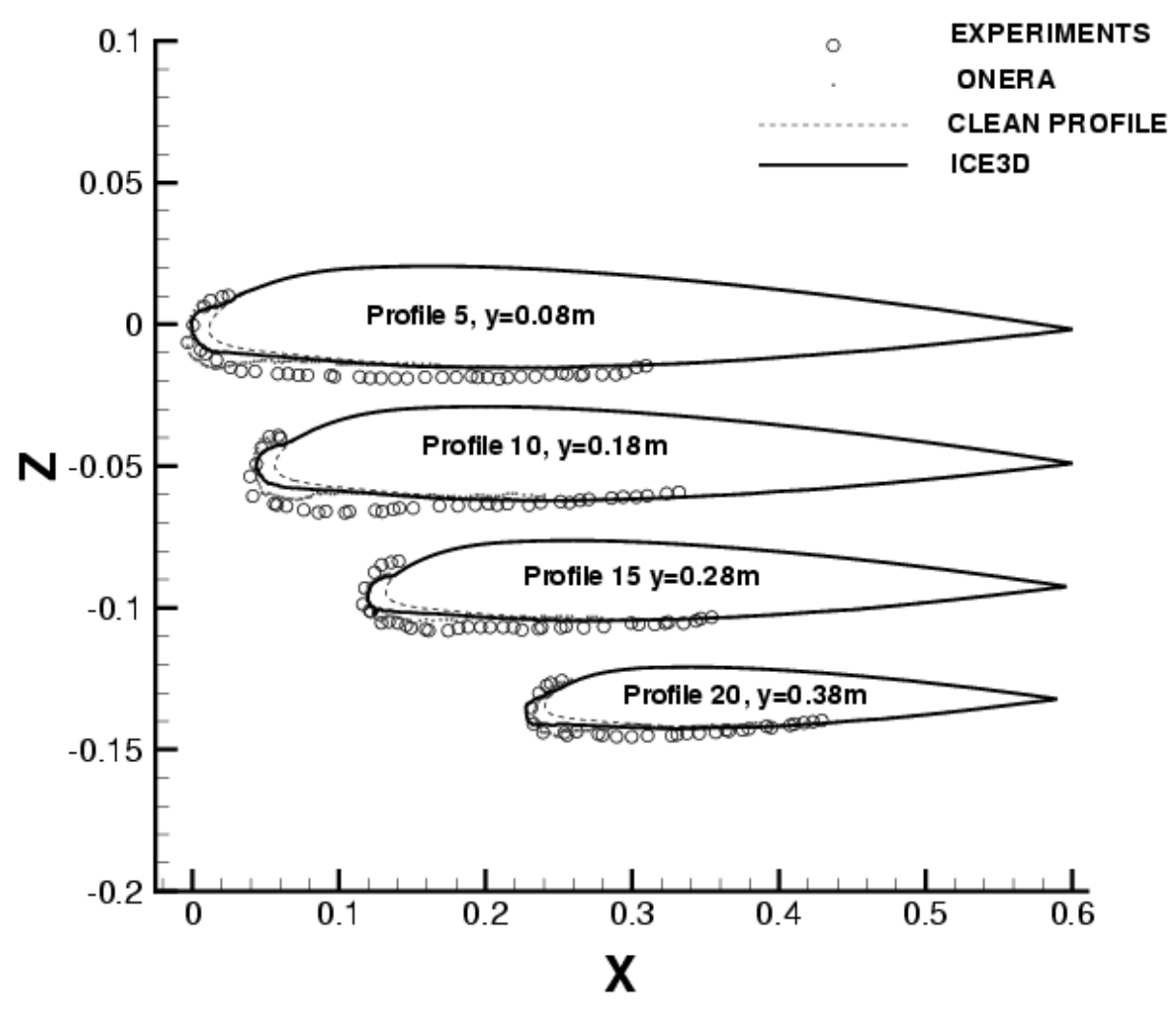

Figure 12: 2D ice cuts along the spanwise direction for stations 1, 2, 3 and 4 
Development of a Second Generation In-flight Icing Simulation Code

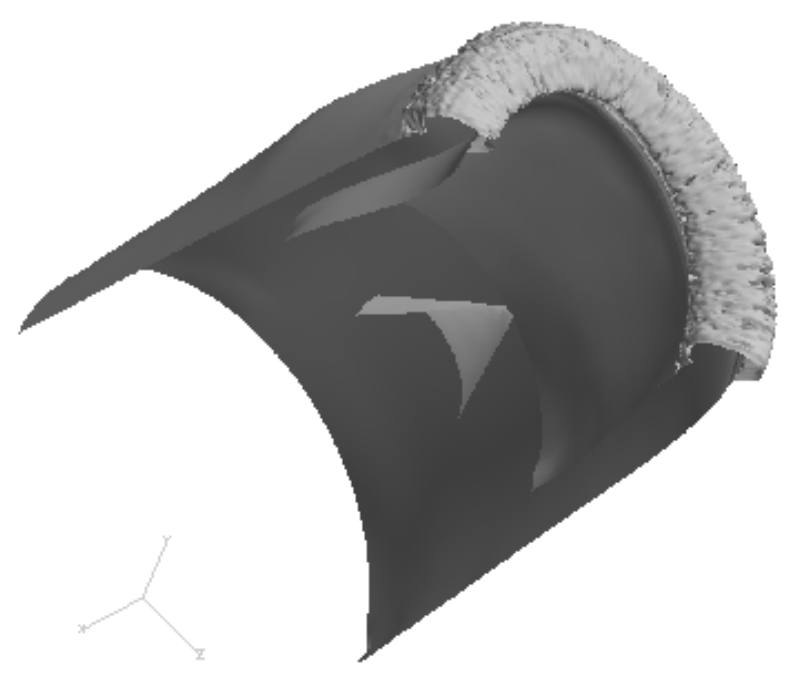

Figure 13: 3D ice accretion on the Boeing 737-300 inlet, rime ice accretion for $15^{\circ} \mathrm{AoA}$ and an inlet mass flow of $10.4 \mathrm{~kg} / \mathrm{s}$ 
Development of a Second Generation In-flight Icing Simulation Code

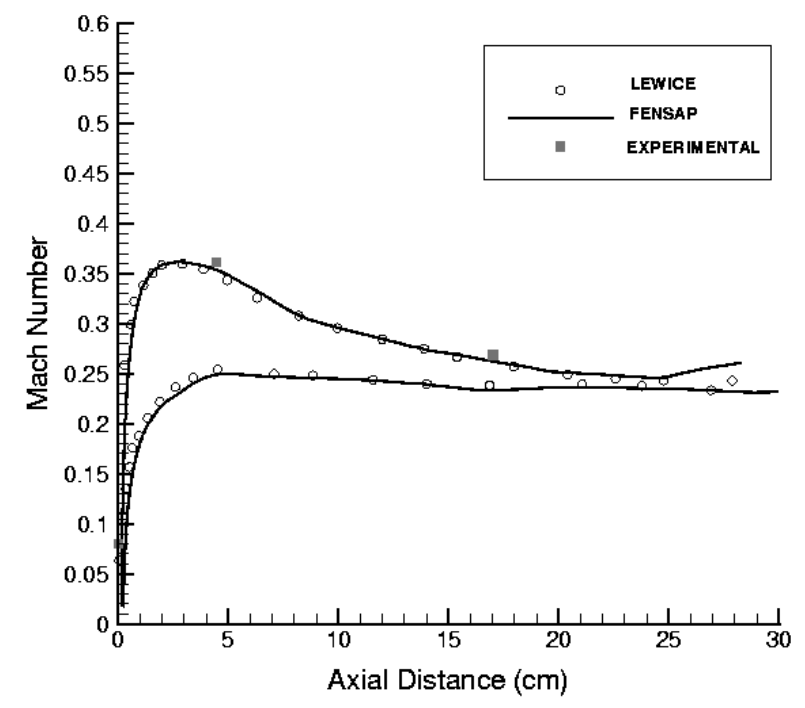

Figure 14: Mach number distribution for the Boeing 737-300 inlet for 0 deg AoA and an inlet mass flow of 10.4 kg/s, comparison between FENSAP, LEWICE and Experiments, circumferential cut 45 deg 
Development of a Second Generation In-flight Icing Simulation Code

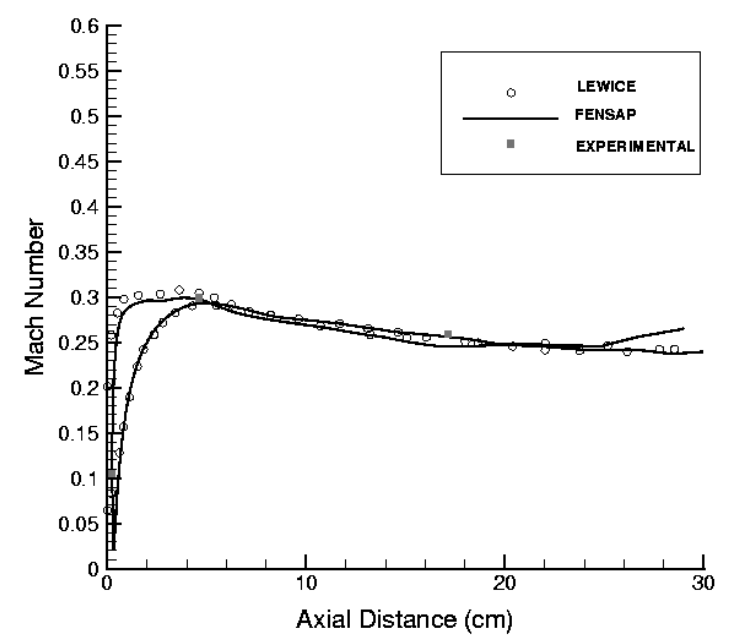

Figure 15: Mach number distribution for the Boeing 737-300 inlet for 15 deg AoA and an inlet mass flow of 10.4 kg/s, comparison between FENSAP, LEWICE and Experiments, circumferential cut 45 deg 
Development of a Second Generation In-flight Icing Simulation Code

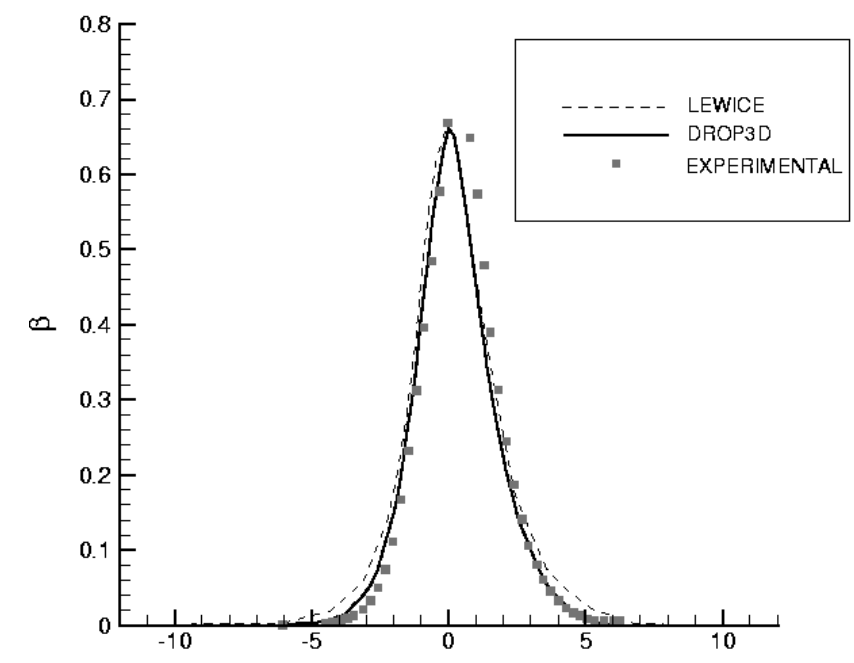

Figure 16: Local collection efficiency distribution for $0^{\circ}$ AoA, comparison between DROP3D, LEWICE and Experiments, circumferential cut $180 \mathrm{deg}$ 
Development of a Second Generation In-flight Icing Simulation Code

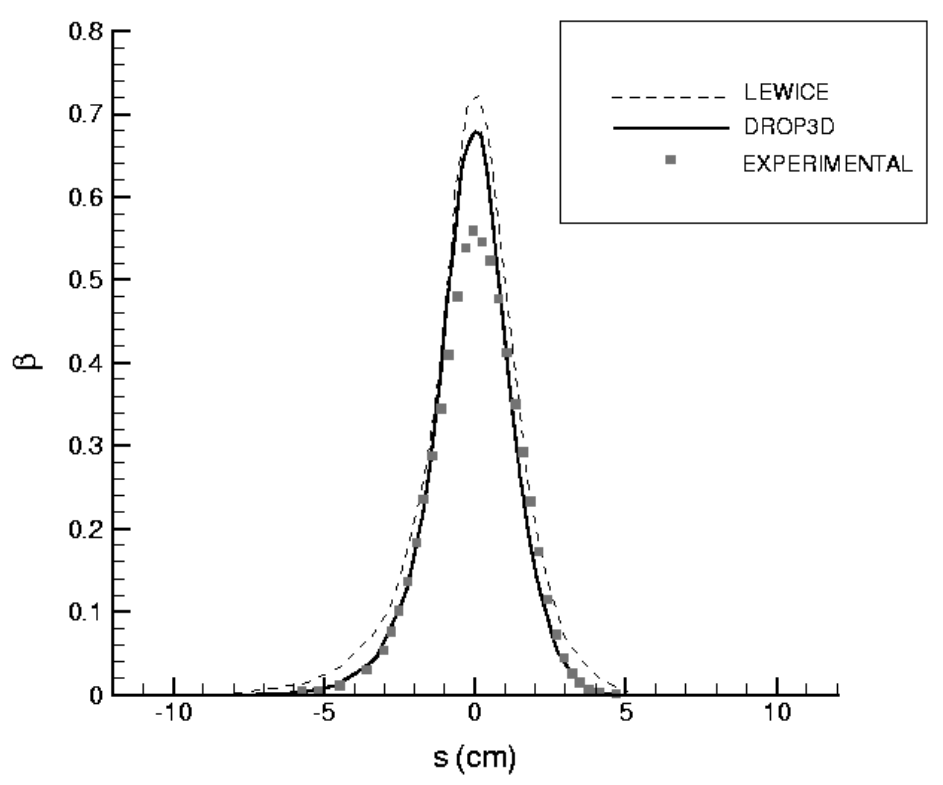

Figure 17: Local collection efficiency distribution for $15^{\circ}$ AoA, comparison between DROP3D, LEWICE and Experiments, circumferential cut $90 \mathrm{deg}$ 
Development of a Second Generation In-flight Icing Simulation Code

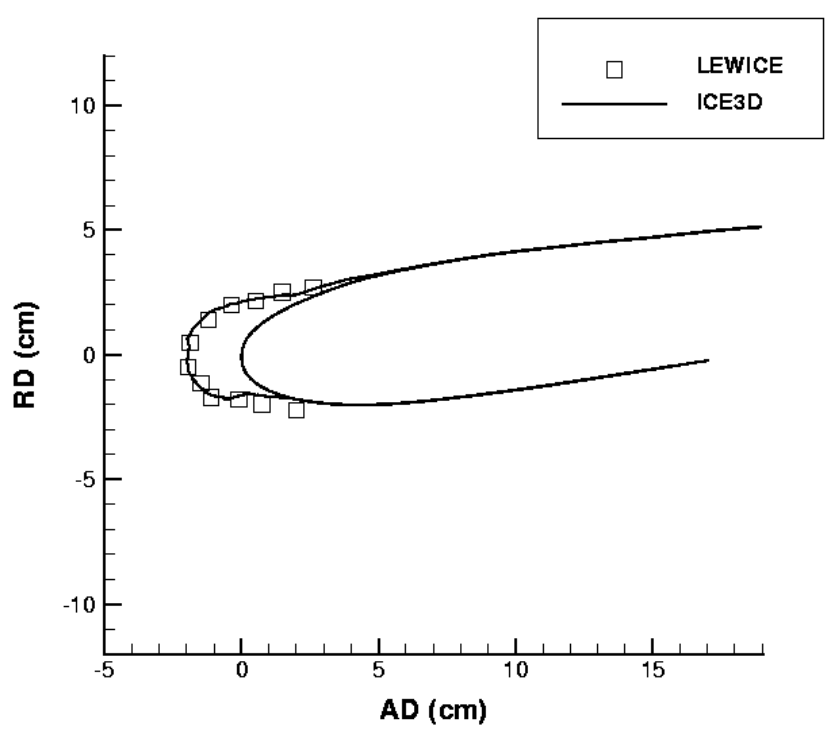

Figure 18: Rime ice for the Boeing 737-300 inlet for $0^{\circ}$ AoA, comparison of analytical ice shapes between ICE3D \& LEWICE, circumferential cut $45 \mathrm{deg}$ 
Development of a Second Generation In-flight Icing Simulation Code

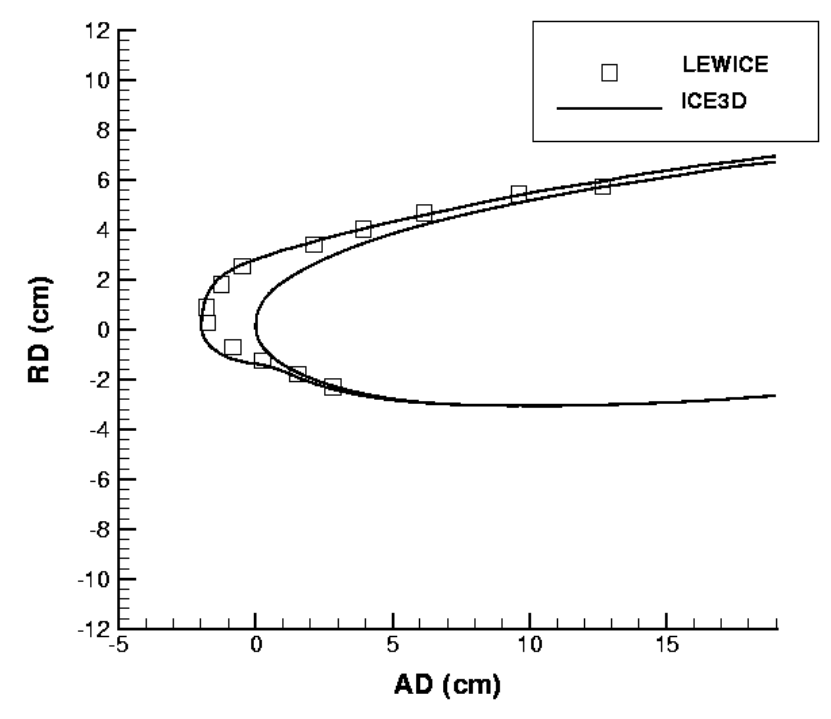

Figure 19: Rime ice for the Boeing 737-300 inlet for $15^{\circ} \mathrm{AoA}$, comparison of analytical ice shapes between ICE3D \& LEWICE, circumferential cut 135 deg 
Development of a Second Generation In-flight Icing Simulation Code

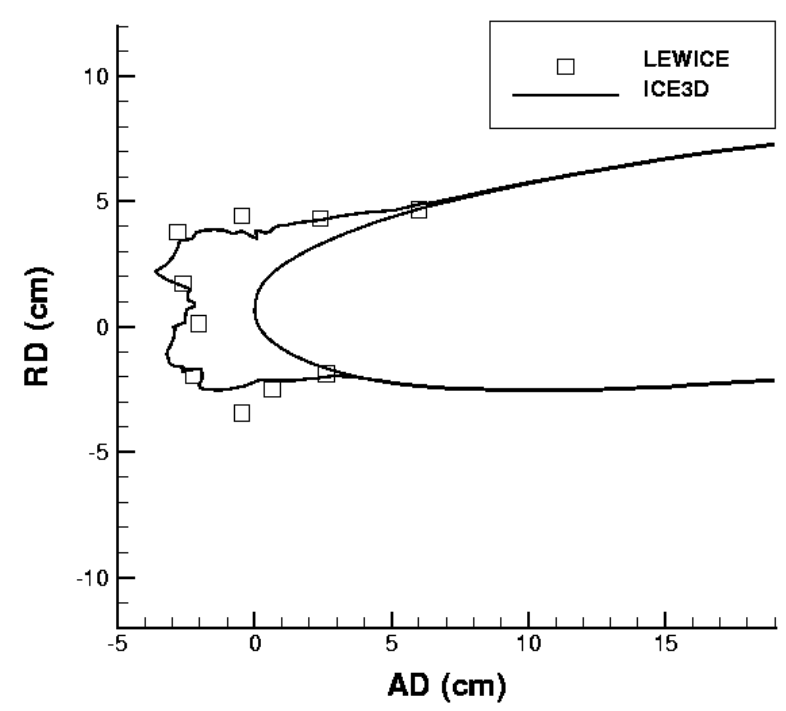

Figure 20: Glaze ice for the Boeing 737-300 inlet for $0^{\circ}$ AoA, comparison of analytical ice shapes between ICE3D \& LEWICE, circumferential cut 135 deg 
Development of a Second Generation In-flight Icing Simulation Code

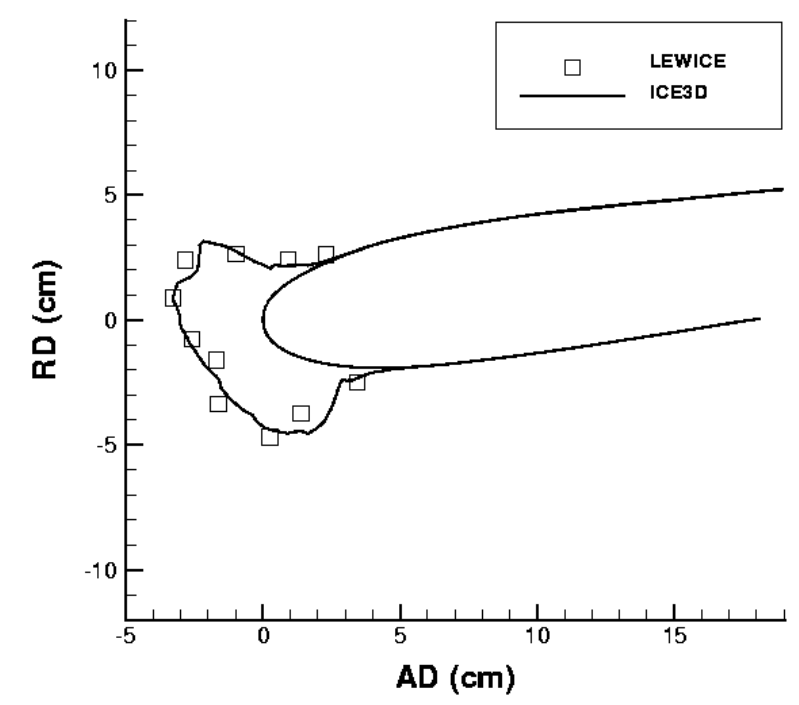

Figure 21: Glaze ice for the Boeing 737-300 inlet for $15^{\circ}$ AoA, comparison of analytical ice shapes between ICE3D \& LEWICE, circumferential cut 45 deg 
Development of a Second Generation In-flight Icing Simulation Code

\section{REFERENCES}

[1] Messinger, B. L., 1953, "Equilibrium Temperature of an Unheated Icing Surface as a Function of Air Speed”, Journal of the Aeronautical Sciences, 20, pp. 29-42

[2] MacArthur C.D., 1983, “Numerical Simulation of Airfoils Ice Accretion ”, AIAA Paper 83-0112.

[3] Ruff, G.A. and Berkowitz, M., May 1990, "Users Manual for the NASA Lewis Ice Accretion Prediction Code (LEWICE)", NASA Contractor Report 185129.

[4] Hedde, T. and Guffond D., June 1995, "ONERA Three-Dimensional Icing Model", AIAA Journal, 33(6), pp. $1038-1045$.

[5] Tran, P., Brahimi, M.T. and Paraschivoiu, I., 1994, "Ice Accretion on Aircraft Wings with Thermodynamic Effects", AIAA Paper 94-0605.

[6] Bidwell, C., Pinella, D. and Garrison, P., 1999, “Ice Accretion Calculation for a Commercial Transport Using the LEWICE3D, ICEGRID3D and CMARC Programs”, AIAA Paper 99-0250

[7] Baruzzi, G.S., Habashi, W.G., Guèvremont, G. and Hafez, M.M., 1995,."A Second Order Finite Element Method for the Solution of the Transonic Euler and Navier-Stokes Equations", International Journal for Numerical Methods in Fluids, 20, pp. 671-693.

[8] Bourgault, Y., Habashi, W.G., Dompierre, J. and Baruzzi, G.S., 1999., "A Finite Element Method Study of Eulerian Droplets Impingement Models", International Journal for Numerical Methods in Fluids, 29, pp. 429-449.

[9] Beaugendre, H., Morency, F. and Habashi, W.G., 2003,"FENSAP-ICE`s Three-Dimensional In-flight Ice Accretion Module", Journal of Aircraft, 40(2), pp. 239-247.

[10] Croce, G., Beaugendre, H. and Habashi, W.G., 2002, "CHT3D: FENSAP-ICE Conjugate Heat Transfer Computations with Droplet Impingement and Runback Effects", AIAA Paper 2002-0386.

[11] Spalart, Ph.R. and Allmaras, S.R., 1992, "A One-Equation Turbulence Model for Aerodynamic Flows", AIAA Paper 92-0439. 
Development of a Second Generation In-flight Icing Simulation Code

[12] Spalart, P.R., 2000, “Trends in Turbulence Treatments”, AIAA Paper 2000-2306

[13] Beaugendre, H., Morency, F. and Habashi, W. G., 2003, "Roughness Implementation in FENSAP-ICE: Model Calibration and Influence on Ice Shapes”, Journal of Aircraft, 40, pp. 1212-1215

[14] Beaugendre, H., 2003, “A PDE-Based 3D Approach for In-Flight Ice Accretion”, Ph. D. Dissertation, McGill University, Montreal, QC, Canada

[15] Habashi, W.G., Dompierre, J., Bourgault, Y., Fortin, M. and Vallet, M.-G., 1998, “Certifiable Computational Fluid Dynamics Through Mesh Optimization”, Special Issue on Credible Computational Fluid Dynamics Simulation, AIAA Journal, 36(5), pp. 703-711

[16] Gresho, P.M., Lee R.L., Sani, R.L., Maslanik, M.K. and Eaton, B.E., 1987, "The consistent Galerkin FEM for Computing Derived Boundary Quantities in Thermal and/or Fluid Problems", International Journal for Numerical Methods in Fluids, 7, pp. 371-394.

[17] Jackson, R., 2000, The Dynamics of Fluidized Particles, Cambridge University Press, Cambridge, Chapter 2.

[18] Hughes, T.J.R. and Brooks A., 1982, “A Theoretical Framework for Petrov-Galerkin Methods with Discontinuous Weighting Functions: Application to the Streamline-Upwind Procedure”, Finite Element in Fluids, Volume 4, Chapter 3, Edited by R.H. Gallagher, D.H. Norrie, J.T. Oden and O.C. Zienckiewicz, John Wiley.

[19] Bourgault, Y., Beaugendre, H. and Habashi, W.G., 2000, "Development of a Shallow Water Icing Model in FENSAP-ICE", Journal of Aircraft, 37, pp. 640-646.

[20] Kays, W. M., and Crawford, B. M., 1993, Convective Heat and Mass Transfer, Mc Graw-Hill, third edition.

[21] Wright W.B. and Rutkowski A., “Validation Results for LEWICE 2.0” and CD-ROM, January 1999.

[22] SAE Recommended Practice for Droplet Impingement and Ice Accretion Computer Codes, ARP5903, 2003.

[23] Kind R.J., “Ice Accretion Simulation Evaluation Test”, NATO RTO Technical Report 38, RTO-TR-038, France, November 2001. 
Development of a Second Generation In-flight Icing Simulation Code

[24] Lepage, C.Y., Suerich-Gulick, F. and Habashi. W.G, 2002., "Anisotropic 3D Mesh Adaptation on Unstructured Hybrid Meshes", AIAA Paper 2002-0859.

[25] Dompierre, J., Vallet, M.-G., Bourgault, Y., Fortin, M. and Habashi, W.G., June 2002, “Anisotropic Mesh Adaptation: Towards User-Independent, Mesh-Independent and Solver-Independent CFD Solutions: Part III: Unstructured Meshes”, International Journal for Numerical Methods in Fluids, 39, pp. 675-702

[26] Roache, P. J., 1998, Verification and Validation in Computational Science and Engineering, Hermosa publishers, Albuquerque, New Mexico, USA, Chapter 5.

[27] Papadakis, M., Elangonan, R., Freund, G.A., Breer, J.M., Zumwalt, G.W. and Whitmer, L., 1989, "An Experimental Method for Measuring Water Droplet Impingement Efficiency on Two- and Three-Dimensional Bodies", NASA CR-4257, DOT/FAA/CT-87/22.

[28] Bidwell, C.S., 1996,"Collection Efficiency and Ice Accretion Calculations for a Boeing 737-300 Inlet", SAE Paper 965570.

[29] Tran, P., Benquet, P., Baruzzi, G. and Habashi, W.G., 2002, "Design of Ice Protection Systems and Icing Certification Through Cost-Effective Use of CFD", AIAA Paper 2002-0382. 